\title{
An Application of Apo(a) Isoforms for the Clinical Assessment of Lp(a)
}

\author{
Shigenobu Takayama, ${ }^{1,4 *}$ Yoko Yasumuro, ${ }^{2}$ Jae-hyuk Kim, ${ }^{3}$ Masashi Ishikawa, ${ }^{3}$ \\ Daijirou Tsujino, ${ }^{3}$ Sumitaka Matsuo, ${ }^{4}$ \\ Yoshiteru Harada, ${ }^{4}$ and Shunji Sugii ${ }^{5}$
}

${ }^{1}$ Division of Laboratory Research, St. Marianna University Yokohamashi Seibu Hospital, Kanagawa-ken, Japan

${ }^{2}$ Division of Clinical Laboratory, St. Marianna University Hospital, Kanagawa-ken, Japan

${ }^{3}$ Division of Metabolism and Endocrinology, St. Marianna University Yokohamashi Seibu Hospital, Kanagawa-ken, Japan

${ }^{4}$ Department of Pharmacology, School of Allied Health Science, Kitasato University, Sagamihara, Japan

${ }^{5}$ Department of Veterinary Medicine, College of Agriculture, Osaka University, Osaka, Japan

\begin{abstract}
To examine whether or not $L p(a)$ is applicable as a diagnostic marker for atherosclerosis, we studied the correlation between $\mathrm{Lp}$ (a) levels and molecular weights of apo(a) isoforms in sera from both normal healthy adults and diabetic patients. Serum Lp(a) level was measured by turbidimetric immunoassay (TIA) and the molecular weight of apo(a) isoform was determined by Western blotting analysis. The serum $L p(a)$ levels of the diabetic patients $(25.0 \mathrm{mg} / \mathrm{dl} \pm 2.2$ [mean $\pm \mathrm{SE}$ ], $\mathrm{n}=54$ ) were significantly higher than those of the normal subjects $(14.4 \mathrm{mg} / \mathrm{dl} \pm 0.57, \mathrm{n}=$ 500). With respect to the correlation between serum $L p(a)$ levels and the molecular weights of apo(a) isoforms, there was an inverse correlation in sera from normal subjects $(n=298)$, whereas there was no correlation in sera from the diabetic patients. Statistical significant in-
\end{abstract}

verse correlation $(r=-0.91, y=224.25-$ $3.07 \mathrm{x}$ ) was especially observed in 50 representative apo(a) isotypes from the normal subjects. By applying a standardized curve based on the significant inverse correlation to serum $L p(a)$ levels, $40.7 \%(22 / 54)$ of the diabetic patients were revealed to have an abnormally high value of serum $L p(a)$. Moreover, it was found that the significantly higher mean value of serum $L p(a)$ in the diabetic group was caused by the 22 patients with higher value of $L p(a)$. The present findings suggest that determination of apo(a) isoform size provides estimation of the serum $L p(a)$ value and that the inverse correlation curve between serum $L p(a)$ level and the molecular weight of apo(a) isoform may be applicable to the clinical use of $L p(a)$. J. Clin. Lab. Anal. 14:53-58, 2000. (c) 2000 Wiley-Liss, Inc.

Key words: $L p(a)$ level; apo(a) isoform; inheriting plasma protein; inverse correlation

\section{INTRODUCTION}

Lipoprotein (a) [Lp(a)] was discovered as an inheriting plasma protein (1). The $\mathrm{Lp}(\mathrm{a})$ molecule consists of two major structural subunits of apolipoprotein(a) [apo(a)] domain and "LDL-like" domain with apo B-100. Because the serum Lp(a) level closely correlates to the molecular weight of apo(a) isoprotein designated "apo(a) isoform," which has been supposed to be dependent on the numbers of repeated kringleIVs located on the apo(a) gene, the serum Lp(a) level and molecular size of apo(a) isoform significantly exhibit the polymorphism (2-8). Besides, Lp(a) has been widely accepted as an independent serum lipoprotein since its serological characteristics are quite different from those of other serum lipoproteins $(9,10)$.

There are several reports on a correlation between the serum $L p(a)$ level and several heart diseases (11-15), suggest- ing that the high serum $\mathrm{Lp}$ (a) level may be associated with the progression of coronary artery dysfunction. Moreover, the correlation between the high serum Lp(a) levels and diabetic patients, especially those with macro-angiopathic disease, has been reported $(16,17)$. For determination of the serum $L p(a)$ level, quantitative assays using the specific polyclonal or

Abbreviations: Lp(a), lipoprotein(a); apo(a), apolipoprotein(a); TIA, turbidimetric immunoassay; SDS-PAGE, sodium dodecyl sulfate-polyacrylamide gel electrophoresis; TTBS, Tween Tris-buffered saline; PVDF, polyvinylidenefluoride; ABC method, avidin-biotin complex method.

*Correspondence to: Shigenobu Takayama, Division of Laboratory Research, St. Marianna University Yokohamashi Seibu Hospital, 1197-1 Yazashi Asahiku, Yokohama-shi, Kanagawa-ken 241, Japan.

E-mail: stakayam@mb.kcom.ne.jp

Received 18 June 1999; Accepted 11 October 1999 
monoclonal antibody against apo(a) are, currently, routinely performed (18). However, since serum Lp(a) level is originally correlated to the molecular weight of the apo(a) isoform and is individually different even in healthy subjects (1921), the quantitative evaluation only by a comparison with a mean value quoted from the general population is not suitable for clinical use of $\mathrm{Lp}(\mathrm{a})$.

To study whether or not $\mathrm{Lp}(\mathrm{a})$ is a candidate for a clinical marker for atherosclerosis, we investigated the relationship between serum Lp(a) levels and the molecular weight of the apo(a) isoform in normal healthy subjects. By using the inverse correlation between them as a standard curve, the $\mathrm{Lp}(\mathrm{a})$ levels in sera from diabetic patients were tentatively estimated on the basis of the apo(a) isoform size. The abnormally high values of $\mathrm{Lp}(\mathrm{a})$ observed in the diabetic patients suggest that the standardized curve based on the inverse correlation between the Lp(a) level and the molecular size of apo(a) isoform may be useful to clinically estimate individual Lp(a) levels.

\section{MATERIALS AND METHODS}

\section{Sera}

Fresh sera were obtained from 500 normal healthy adults who lacked any obvious clinical presentation [male: 228; female: 272; age $33.9 \pm 10.8$ years (SD)] previously confirmed to be normolipidemic and 54 (Type 1: 4; Type 2: 50) diabetic patients (male: 30 ; female: 24 ; age $53.9 \pm 14.1$ years) were studied. This study was approved by the ethics committees of the relevant institutions and was performed in compliance with the Declaration of Helsinki.

\section{Determination of Serum Lp(a) Concentration}

Serum Lp(a) concentration was determined with a commercial Lp(a) assay kit (Cosmo Bio Co., Tokyo, Japan) (18). $\mathrm{Lp}$ (a) at 0.5 to $150 \mathrm{mg} / \mathrm{dl}$ was detectable by turbidimetric immunoassay (TIA) using the kit.

\section{Western Blotting to Analyze Apo(a) Isoform}

Two $\mu$ l of serum sample dissolved in $48 \mu 1$ of SDS-PAGE buffer (10 mM Tris- $\mathrm{HCl} \mathrm{pH} 8.0$, containing $1 \mathrm{mM}$ EDTA, $2.5 \%$ SDS, $10 \%$ glycerol, and 5\% 2-mercaptoethanol) was incubated for $30 \mathrm{~min}$ at $60^{\circ} \mathrm{C}$. Then one $\mu \mathrm{l}$ of the sample mixture was applied on 4-15\% gradient polyacrylamide gel (Pharmacia, Uppsala, Sweden). The electrophoresis procedure involved the following three steps, which consisted of $15^{\circ} \mathrm{C} / 1 \mathrm{Vh} / 10 \mathrm{~mA}, 15^{\circ} \mathrm{C} / 1 \mathrm{Vh} / 1 \mathrm{~mA}$ and $15^{\circ} \mathrm{C} / 300 \mathrm{Vh} / 10$ mA. Biotinylated SDS-PAGE standards (High Range, BioRad, CA) and purified human apolipoprotein B-100 (Organon Teknika, Tokyo, Japan) were used as a molecular size marker. After electrophoresis, separated proteins were electrophoretically transferred to PVDF-membrane (Immobilon-P, Millipore, Bedford, MA ) under a condition of $25 \mathrm{~mA} / \mathrm{gel}$ for $90 \mathrm{~min}$ at $15^{\circ} \mathrm{C}$. All procedures for electro- phoresis were performed with PhastSystem (Pharmacia, Uppsala, Sweden).

The PVDF-membrane was soaked in TTBS $(0.25 \%$ Tween20 in $20 \mathrm{mM}$ Tris- $\mathrm{HCl}$, pH 7.2 containing $0.9 \% \mathrm{NaCl}$ ) containing $5 \%$ of nonfat dry milk for $2 \mathrm{hr}$, then was washed three times by TTBS. The first immunological reaction was performed with TTBS containing $1 \mu \mathrm{g} \mathrm{ml}^{-1}$ of purified goat antihuman $\mathrm{Lp}$ (a) antibody for $4 \mathrm{hr}$. After washing, the membrane was again soaked in the second reaction mixture consisted of $0.5 \%$ nonfat dry milk-TTBS with $0.5 \mu \mathrm{g} \mathrm{ml}^{-1}$ of biotinylated rabbit antigoat IgG antibody (Vector, CA) for $1.5 \mathrm{hr}$. After washingthe apo(a) moiety was visualized by $\mathrm{ABC}$ method (22) with a POX-conjugated streptoavidin (Amersham, Tokyo, Japan) and a Konica immunostain HRP kit (Konica, Tokyo, Japan). Finally the apo(a) isoform was classified into seven types according to the molecular weight reported by Uterman et al. (8). To confirm the condition on SDS-PAGE, some electrophoresed gels loaded in parallel were also stained by an optimized silver staining method with PhastSystem.

\section{Statistical Analysis}

Data were expressed as the mean \pm SE or SD. A $P$ value of less than 0.05 calculated by nonparametric Mann-Whitney U-test and a $P$ value of less than 0.005 calculated by the Bonferroni/Dunn test were considered significant. Regression calculated by Spearman's single rank test using a $P$ value with a $95 \%$ of confidential rate was also expressed. StatView software (Abacus Concepts, CA) was used for all analyses.

\section{RESULTS}

\section{Determination of $L p(a)$ Level in Sera From Normal Healthy Adults and Diabetic Patients}

To determine the serum Lp(a) level, sera from 500 normal subjects and 54 diabetic patients were obtained. Mean $( \pm$ SE) levels of $\mathrm{Lp}(\mathrm{a})$ were determined by TIA . There was a significant difference $(P<0.001)$ in the $\mathrm{Lp}(\mathrm{a})$ level between the normal subjects $(14.4 \pm 0.57 \mathrm{mg} / \mathrm{dl})$ and the patients $(25.0 \pm$ $2.2 \mathrm{mg} / \mathrm{dl})$, whereas there was no gender difference in both subjects (Fig.1). As shown in Figure 1, the levels of Lp(a) in the normal subjects were widely distributed from 1.0-130 $(\mathrm{mg} / \mathrm{dl})$, whereas those from the diabetic patients were from 2.0-89.0. The highest frequency of Lp(a) levels in both subjects was found at a range of 5.0-15.0 (mg/dl). However, Lp(a) levels at less than $25.0 \mathrm{mg} / \mathrm{dl}$ were found in $85 \%(475 / 500)$ of sera from the normal subjects, as compared to $61.1 \%(33 /$ 54) of sera from the diabetic patients.

\section{Western Blotting to Analyze Apo(a) Isoform(s)}

To study the correlation between the serum Lp(a) levels and the molecular weight of apo(a) isoforms, apo(a) molecules in sera from normal subjects and diabetic patients were analyzed by Western blotting. Two hundred and ninety-eight 

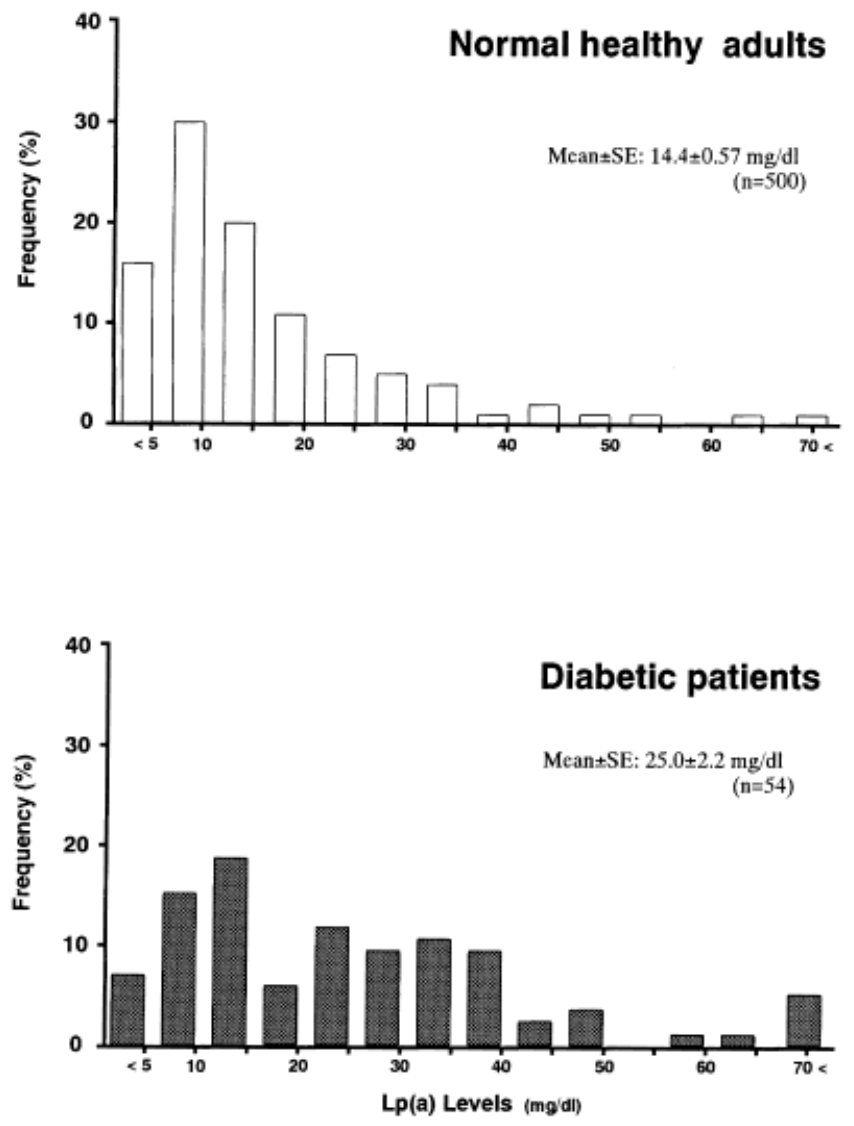

Fig. 1. Histogram of $L p(a)$ levels in normal healthy adults $(n=500)$ and diabetic patients $(\mathrm{n}=54)$. The serum Lp(a) levels $(\mathrm{mg} / \mathrm{dl})$ were measured by a TIA method. The mean $( \pm$ SE) in the diabetic patients was significantly higher than that of the normal healthy adults by analysis of the Mann-Whitney U-test $(P<0.0001)$.

apo(a) isoforms selected randomly from the 500 normal subjects were classified into 7 isotypes according to the previous report (8). Various apo(a) isotypes such as $S 4, S 4 / S 3, S 4 / S 2$, $S 3, S 3 / S 2, S 3 / S 1, S 2, S 2 / S 1, S 1$ and $B$ were observed in 116 (39.1\%), 45 (15.3\%), 25 (8.4\%), 32 (10.7\%), 29 (9.9\%), 2 $(0.8 \%), 23(7.6 \%), 14(4.6 \%), 10(3.4 \%)$ and $2(0.8 \%)$, respectively. The intratypical Lp(a) levels (mean $\pm \mathrm{SD}$ ) of the apo(a) isotypes were $11.2 \pm 5.2$ for $S 4,18.2 \pm 7.1$ for $S 4 / S 3$, $34.4 \pm 8.4$ for $S 4 / S 2,25.2 \pm 6.9$ for $S 3,48.9 \pm 16.4$ for $S 3 / S 2$, $16.1 \pm 7.5$ for $S 3 / S 1,46.9 \pm 7.5$ for $S 2$ isotype, $69.3 \pm 21.5$ for $S 2 / S 1$ isotype, $63.2 \pm 18.3 \mathrm{mg} / \mathrm{dl}$ for $S 1$, and $85.7 \pm 15.3 \mathrm{mg} /$ $\mathrm{dl}$ for $B$, respectively. With respect to the relationship between the serum Lp(a) levels and the molecular weight of the apo(a) isoforms, smaller molecular mass the apo(a) molecule was found in the serum with the higher $\mathrm{Lp}(\mathrm{a})$ level as shown in Figure 2. To confirm the relationship between the serum Lp(a) level and the molecular weight of apo(a) isoform, 50 representative isotypes showed a single apo(a) isoform band, such as $S 4, S 3, S 2, S 1$, and $B$ were again selected from the 298 normal subjects. The mean $( \pm \mathrm{SD})$ value of them was 2.0 to

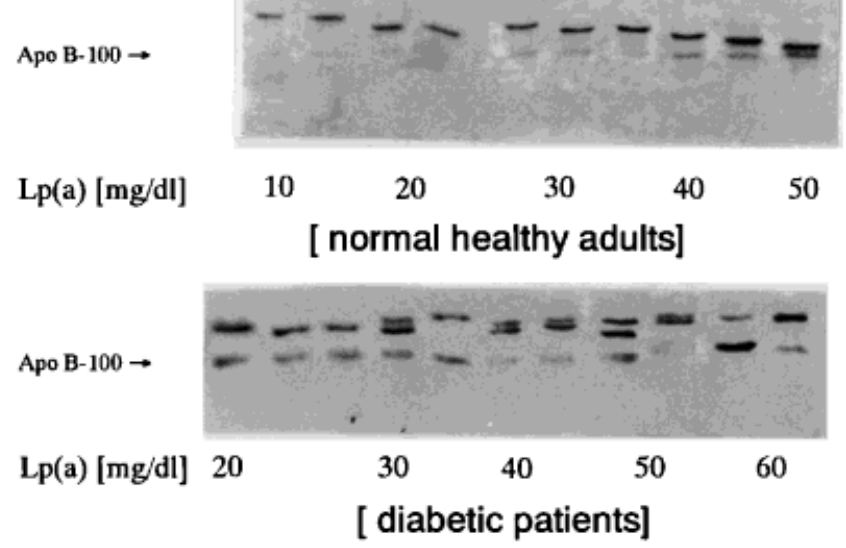

Fig. 2. Polymorphism of apo(a) isoforms on the analysis by Western blotting. Each apo(a) isoform size in the normal subjects showed to become gradually smaller in relation to the elevation of serum Lp(a) levels, respectively. In contrast, apo(a) isoforms in the diabetic patients constantly showed high molecular weights despite having high levels of serum $\mathrm{Lp}(\mathrm{a}) . \rightarrow$ : Apo B-100 (as a molecular weight marker).

$19.0 \mathrm{mg} / \mathrm{dl}(9.8 \pm 5.5[$ mean $\pm \mathrm{SD}], \mathrm{n}=14)$ for $S 4,15.0$ to $42.3 \mathrm{mg} / \mathrm{dl}(25.9 \pm 8.0, \mathrm{n}=13)$ for $S 3,38.0$ to $60.0 \mathrm{mg} / \mathrm{dl}$ $(47.4 \pm 7.9, \mathrm{n}=11)$ for $S 2,40.2$ to $97.0 \mathrm{mg} / \mathrm{dl}(63.3 \pm 18.3, \mathrm{n}$ $=10$ ) for $S 1$, and 70.5 and $101.0 \mathrm{mg} / \mathrm{dl}$ for B, respectively. By analysis of the Bonferroni/Dunn test, a significant difference of $L p(a)$ levels was clearly shown between the representative apo(a) isotypes (Fig. 3). Moreover, the serum Lp(a) levels showed inversely proportional to the molecular weights of the apo(a) isotypes and the linear regression analysis of the relationship by Spearman's rank correlation test gave a significant correlation: $\mathrm{y}=224.25-3.07 \mathrm{x}$ with coefficient of $\mathrm{r}=-0.91(P<0.0001)$.

\section{Relationship Between Lp(a) Levels and the Molecular Weight of Apo(a) Isoforms in Diabetic Patients}

On Western blotting analysis, the density of the apo(a) isoforms in sera from the 54 diabetic patients was found to be similar to that from the normal subjects. However, the apo(a) isoforms such as $S 4$ or $S 3$ with high molecular size were observed in $96.3 \%$ (52/54) of the diabetic patients although high $\mathrm{Lp}$ (a) levels were also observed. The $\mathrm{Lp}$ (a) levels were plotted against the molecular weights of apo(a) isoforms in the diabetic patients (Fig. 4). As shown in Figure 4, 40.7\% (22/ 54) of the $\mathrm{Lp}$ (a) levels among the diabetic patients were apparently higher than the mean \pm 1 SD levels at the corresponding apo(a) isotypes from the normal subjects. The frequency of an abnormally high value of $L p(a)$ levels observed was up to $33.3 \%(6 / 18)$ of sera with a single $S 4$ isotype, $36.4 \%(4 / 11)$ of sera a single $S 3$ isotype, $52.9 \%$ (9/17) of sera with combined $S 3 / S 4$ isotypes, $25 \%$ (1/4) of sera with combined $S 2 / S 4$ isotypes, $50 \%(1 / 2)$ of sera $S 2 / S 3$ isotypes and 


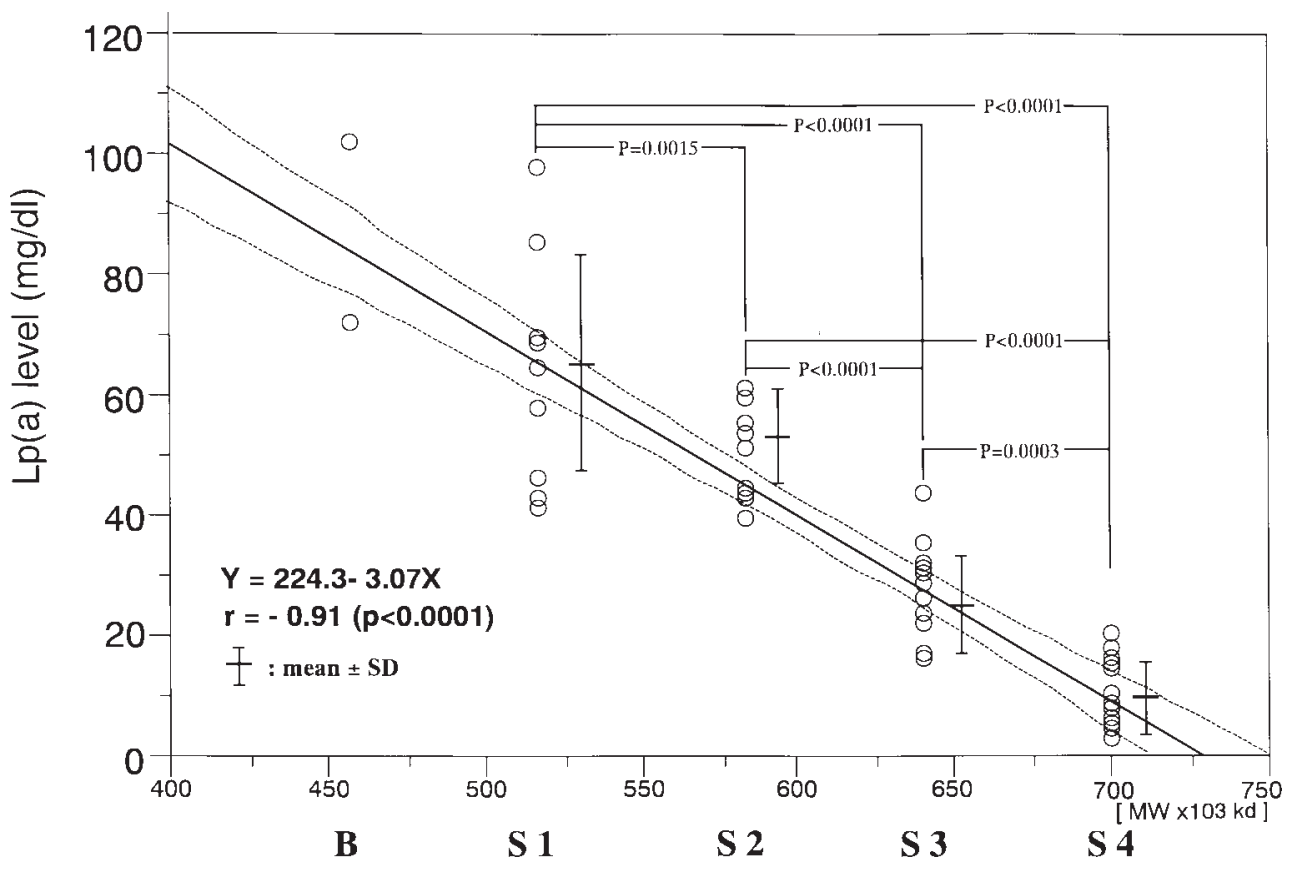

Fig. 3. The correlation between serum $\mathrm{Lp}$ (a) levels and the molecular weights of the apo(a) isotypes in 50 representative apo(a) isotypes extracted from the normal subjects. The statistical significance of serum Lp(a) levels in each apo(a) isotype was analysed by the Bonferroni/Dunn test with the

one serum with $B / S 4$ isotypes, respectively. Many of the diabetic patients with an $S 4$ and/or $S 3$ apo(a) isotype showed abnormally high Lp(a) levels.

\section{DISCUSSION}

There have been many reports that high serum $\operatorname{Lp}(\mathrm{a})$ is closely associated with atherosclerosis (11-15), suggesting that $\mathrm{Lp}(\mathrm{a})$ may be a candidate for use as a clinical indicator for the assessment of atherosclerosis. On the other hand, various micro- and/or macro-angiopathic complications in diabetic patients have been reported (22-25) and the high levels of serum Lp(a) in the diabetic patients have been considered to be possibly associated with the progression of their angiopathical atherosclerosistic dysfunction $(16,17)$. However, a quantitative determination of serum $\mathrm{Lp}$ (a) levels is not enough to reflect the clinical state of atherosclerosis because serum Lp(a) levels are closely correlated with the molecular size of apo(a) isoforms, which vary among individuals (2-8).

Many investigations concerning the influence of aging or gender difference on serum Lp(a) levels have been reported (26-34). Lp(a) levels in infants $(26,27)$ and elderly subjects $(28,29)$ have been reported to be significantly lower than those of healthy adults. Although several reports have shown higher levels of serum $\mathrm{Lp}(\mathrm{a})$ in women $(32,33)$ and postmenopausal women $(30,34)$, the influence of gender difference is still uncertain $(30,31)$. In this study, the mean $( \pm S E)$ values of $L p(a)$ standard $P$ value of $<0.005$, and the inverse correlation curve was calculated by Spearman's rank correlation; Solid line = regression line, dotted line $=95 \%$ confidence intervals curves $($ tied $P<0.0001)$.

levels in 500 healthy normal subjects and 54 diabetic patients were $14.4 \pm 0.57 \mathrm{mg} / \mathrm{dl}$ and $25.0 \pm 2.2 \mathrm{mg} / \mathrm{dl}$, respectively. Although the mean age of the diabetic patients was significantly higher than that of the normal subjects $(P<0.001)$, the $\mathrm{Lp}(\mathrm{a})$ levels in the diabetic patients were significantly higher than those of the normal subjects $(P<0.001)$. Since there was no significant gender difference on the Lp(a) levels in the diabetic patients, these findings have supported previous reports of the higher $\mathrm{Lp}(\mathrm{a})$ levels in diabetic patients $(16,17)$.

We also analyzed 298 apo(a) isoforms among the normal subjects by Western blotting and investigated the relationship between the molecular weight of the apo(a) isoform and the level of serum Lp(a). In the findings obtained, smaller molecular mass of apo(a) molecule found in sera showed higher serum levels of $\operatorname{Lp}(a)(8,19-21)$, indicating that each size of genetically-controlled apo(a) isoforms is closely correlated with the level of serum $\mathrm{Lp}(\mathrm{a})$. Moreover, the $\mathrm{Lp}(\mathrm{a})$ levels obtained from 50 normal sera with representative apo(a) isotypes were significantly different depending on the apo(a) isotype. The inverse correlation between the molecular weights of apo(a) isoform and the levels of serum Lp(a) was supported by the statistical significance(Fig. 3) (35). The mean $( \pm$ SD) value of serum $\mathrm{Lp}(\mathrm{a})$ in every apo(a) isotype in the representative 50 subjects was not significantly different from those of the 298 subjects. In contrast, many of apo(a) isoforms in 54 diabetic patients were found to consist of $S 4$ or $S 3$ with a higher molecular weight although they showed the higher Lp(a) levels (Fig. 2). Therefore, the correlation between the 


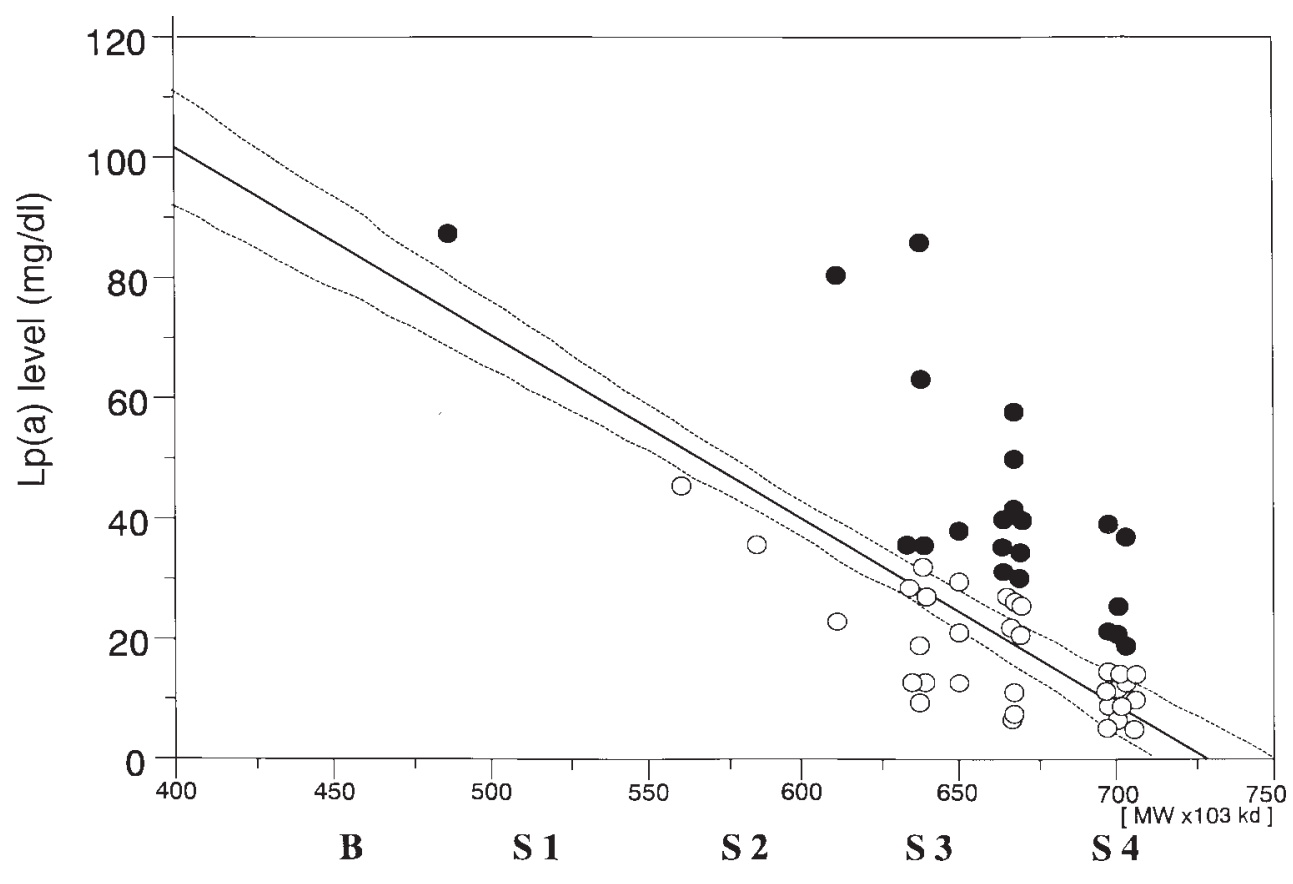

Fig. 4. Evaluation of serum $L p(a)$ levels in the diabetic patients. The $L p(a)$ levels which were higher than the range of mean $\pm 1 \mathrm{SD}$ at the corresponding apo(a) isotypes were expressed as a closed circle,

serum $L p(a)$ levels and the molecular weights of the apo(a) isotypes in the diabetic patients was apparently different from that of the normal subjects (data not shown).

To distinguish between normal and abnormal value of $\mathrm{Lp}$ (a) levels in the diabetic patients, the Lp(a) levels were plotted against the molecular weights of the apo(a) isotypes. According to classification of the serum level of each apo(a) isotype, $40.7 \%$ (22/54) of sera from the patients was clearly revealed quantitative by using a standardized curve based on the significant inverse correlation from the representative 50 subjects. From the findings, it was determined that the significantly higher mean value $(25.0 \pm 2.2 \mathrm{mg} / \mathrm{dl})$ of serum $L p(a)$ obtained from the diabetic group was caused by the 22 patients with higher $\mathrm{Lp}(\mathrm{a})$ values. Therefore, on the basis of apo(a) isoform sizes, the high value of serum $\mathrm{Lp}$ (a) observed in the 22 diabetic patients was concluded to be abnormal. Although there was no significant correlation between the abnormally high $\mathrm{Lp}(\mathrm{a})$ levels and their diabetic complications, such as retinopathy, nephropathy, and neuropathy, these findings in the diabetic patients may be associated with the progression of diabetic angiopathy.

The present findings strongly suggest that determination of the molecular size of apo(a) isoform is important, because the serum $\mathrm{Lp}$ (a) level is estimated by determination of the molecular size of the apo(a) isoform. Moreover, the serum Lp(a) level based on the standardized curve may be applicable to the clinical use of $\operatorname{Lp}(\mathrm{a})$. To clarify the clinical significance of $\mathrm{Lp}(\mathrm{a})$, it may be necessary to confirm whether or not the high serum $\mathrm{Lp}$ (a) level in a patient is in an inheriting value or in an abnormally high value. In terms of clinical assessment of $\mathrm{Lp}(\mathrm{a})$, therefore, it may be also important to establish the inheriting correlation between serum Lp(a) levels and the apo(a) isoform sizes.

\section{REFERENCES}

1. Berg K. A new serum type system in man-the Lp-system. Acta. Pathol. Microbiol. Scand 1963;59:369-382.

2. Fless GM, Rolih CA, Scanu AM. Heterogeneity of human plasma lipoprotein(a). Isolation and characterization of the lipoprotein subspecies and their apoproteins. J Biol Chem 1984;259:1470-1478.

3. Fless GM, ZumMallen ME, Scanu AM. Isolation of apolipoprotein(a) from lipoprotein(a). J Lipid Res 1985;26:1224-1229.

4. Gaubatz JW, Heideman C, Gotto Jr AM, Morrisett JD, Dahlen GH. Human plasma lipoprotein[a]. Structural properties. J Biol Chem 1983;258:4582-4589.

5. Gaw A, Boerwinkle E, Cohen LC, Hobbs HH. Comparative analysis of the apo(a) gene, apo(a) glycoprotein, and plasma concentrations of $\mathrm{Lp}$ (a) in three ethnic groups. J Clin Invest 1994;93:2526-2534.

6. Scanu AM. Stractural and functional polymorphism of lipoprotein (a): biological and clinical implications. Clin Chem 1995;41:170-172.

7. Trieu VN, Zioncheck TF, Lawn RM, McConathy WJ. Interaction of apolipoprotein(a) with apolipoprotein B-containing lipoproteins.J Biol Chem 1991;266:5480-5485.

8. Utermann G, Menzel HJ, Kraft HG, Duba CH, Kemmler HG, Seitz C. $\mathrm{Lp}$ (a) glycoprotein phenotype. Inheritance and relation to Lp(a)-lipoprotein concentration in plasma. J Clin Invest 1987;80:458-465.

9. Loscalzo J. Lipoprotein (a). A unique risk factor for atherothrombotic disease. Atherosclerosis 1990;10:672-679.

10. Sandkamp M, Funke H, Schulte H, Kohler E, Assmann G. Lipoprotein (a) is an independent risk factor for myocardial infarction at a young age. Clin Chem 1990;36:20-23.

11. Armstrong VW, Cremer P, Eberle E, et al. The association between se- 
rum $\mathrm{Lp}$ (a) concentration and angiopathically assessed coronary atherosclerosis. Dependence on serum LDL level. Atherosclerosis 1986; 62:249-257.

12. Dahlen GH, Guyton JR, Attar M, Farmer JA, Kautz JA, Gotto Jr AM. Association of levels of lipoprotein Lp(a), plasma lipids, and other lipoproteins with coronary artery disease documented by angiopathy. Circulation 1986;74:758-765.

13. Koltringer P, Jurgens G. A dominant role of lipoprotein(a) in the development of cervical atherosclerosis. Atherosclerosis 1985;58:187-198.

14. RenningerW, Wendt GG, Nawrocki P, Weigand H. Contribution to problems of the Lp-systems. Humangenetik 1965;1:658-667.

15. Zenker G, Koltringer P, Bone G, Niederkom K, Pfeiffer KP, Jurgens G. Lipoprotein (a) as a strong indicator for cerebrovascular disease. Stroke 1986;17:942-945.

16. Bruckert E, Davidoff P, Grimaldi A, et al. Increased serum levels of lipoprotein(a) in diabetes mellitus and their reduction with glycemic control. JAMA 1990;263:35-36.

17. Heller FR, Jamart J, Honore P, et al. Serum lipoprotein(a) in patient with diabetes mellitus. Diabetes Care 1993;16:819-823.

18. Megoro T, Ohbayashi S, Sudou T, Takayama S, Shiga K, Tateshita T. Fundamental and clinical study of TIA method for the quantification of serum Lp(a). Igaku to Yakugaku 1994;31:989-993.

19. Sandholzer C, Hallmann DM, Sala N. Effects of apolipoprotein(a) size polymorphism on the lipoprotein(a) concentration in 7 ethnic groups. Human Genet 1991;86:607-614.

20. Boerwinkle E, Leffert CC, Lin J, Lackner C, Chiesa G, Hobbs HH. Apolipoprotein(a) gene accounts for greater than $90 \%$ of the variation in plasma lipoprotein(a) concentrations. J Clin Invest 1992;90:52-60.

21. Gaubatz JW, Ghanem KI, Guevara Jr. Nava ML, Patsch W, Morriset JD. Polymorphic forms of human apolipoprotein(a): inheritance and relationship of their molecular weights to plasma levels of lipoprotein(a). J Lipid Res 1990;31:603-613.

22. Hsu SM, Raine L. Protein A, avidin, and biotin in immunohistochemistry. J Histochem Cytochem 1981;29:1349-1359.

23. Assmann G, Schutle H. The prospective cardiovascular munster (PROCAM) study: prevalence of hyperlipidemia in persons with hypertension and/or diabetes mellitus and the relationship to coronary heart disease. Am Heart J 1988;116:1713-1724.
24. Kannel WB, MoGee DL. Diabetes and cardiovascular risk factors. The Framingham study. Circulation 1979;59:8-13.

25. Stamler J, Vaccaro O, Neaton JD, Wentworth D, Group MR. Diabetes, other risk factors, and 12-yr. cardiovascular mortality for men screened in the Multiple Risk Factor Investigation Trial. Diabetes Care 1993;16:434-444.

26. Wood WG, Schumacher M, Weigert S. (Apo)lipoprotein(a) concentrations at birth and in the first days and months of life-studies on the distribution of serum levels and the predictive value of measurements made at this time. Eur J Clin Chem Clin Biochem 1995;33:139-145.

27. Rifai N, Heiss G, Doetsch K. Lipoprotein(a) at birth, in blacks and whites. Atherosclerosis 1992;92:123-129.

28. Knapp RG, Schreiner PJ, Sutherland SE, et al. Serum lipoprotein(a) levels in elderly black and white men in the Charleston Heart Study. Clin Genet 1993;44:225-231.

29. Kario K, Matsuo T, Imiya M, et al. Close relation between lipoprotein (a) levels and atherothrombotic disease in Japanese subjects $>75$ years of age. Am J Cardiol 1994;15:1187-1190.

30. Jenner JL, Ordovas JM, Lamon-Fava S, Schaefer MM, Wilson PW, Castelli WP, Schaefer EJ. Effects of age, sex, and menopausal status on plasma lipoprotein(a) levels. The Framingham Offspring Study. Circulation 1993;87:1135-1141.

31. Slunga L, Asplund K, Johnson O, Dahlen GH. Lipoprotein (a) in a randomly selected 25-64 year old population: the Northern Sweden Monica Study. J Clin Epidemiol_1993;46:617-624.

32. Brown SA, Hutchinson R, Morrisett J, Boerwinkle E, Davis CE, Gotto AM Jr, Patsch W. Plasma lipid, lipoprotein cholesterol, and apoprotein distributions in selected US communities. The Atherosclerosis Risk in Communities (ARIC) Study. Arterioscler Thromb 1993;13:1139-1158.

33. Bovet P, Rickenbach M, Wietlisbach V, Riesen W, Shamlaye C, Darioli R, Burnand B. Comparison of serum lipoprotein(a) distribution and its correlates among black and white populations. Int J Epidemiol 1994;23:20-27.

34. Nago N, Kayaba K, Hiraoka J, et al. Lipoprotein(a) levels in the Japanese population: influence of age and sex, and relation to atherosclerotic risk factors. The Jichi Medical School Cohort Study. Am J Epidemiol 1995;141:815-821.

35. Hata Y, editor. Lipoprotein(a)—Kiso to Rinshou. Tokyo:Kyouwa Kikaku, Inc.; 1998. 267 p. 